\title{
Light-Up Probes: Thiazole Orange-Conjugated Peptide Nucleic Acid for Detection of Target Nucleic Acid
}

\section{in Homogeneous Solution}

\author{
Nicke Svanvik,* Gunnar Westman,† Dongyuan Wang,* and Mikael Kubista*,1 \\ *Department of Mol ecular Biotechnol ogy, Lundberg I nstitute, S-413 90, Göteborg, Sweden; and \\ tDepartment of Organic Chemistry, Chalmers University of Technol ogy, S-413 90, Göteborg, Sweden
}

\begin{abstract}
We have constructed light-up probes for nucleic acid detection. The light-up probe is a peptide nucleic acid (PNA) oligonucleotide to which the asymmetric cyanine dye thiazole orange (TO) is tethered. It combines the excellent hybridization properties of PNA and the large fluorescence enhancement of TO upon binding to DNA. When the PNA hybridizes to target DNA, the dye binds and becomes fluorescent. $F$ ree probes have low fluorescence, which may increase almost 50-fold upon hybridization to complementary nucleic acid. This makes the light-up probes particularly suitable for homogeneous hybridization assays, where separation of the bound and free probe is not necessary. We find that the fluorescence enhancement upon hybridization varies among different probes, which is mainly due to variations in free probe fluorescence. For eight probes studied the fluorescence quantum yield at $25^{\circ} \mathrm{C}$ in the unbound state ranged from 0.0015 to 0.08 and seemed to depend mainly on the PNA sequence. The binding of the light-up probes to target DNA is highly sequence specific and a single mismatch in a 10-mer target sequence was readily identified. ( 2000 Academic Press
\end{abstract}

Key Words: homogeneous assays; PNA; peptide nucleic acid; fluorescent hybridization probe; asymmetric cyanine dye; thiazole orange.

As the exploration of gene organization and function is applied to clinical diagnostics, the need for rapid and cost-efficient methods to detect specific nucleic acid sequences is growing. Most methods involve hybridization of sequence specific probes to target nucleic acids.

\footnotetext{
${ }^{1}$ To whom correspondence and reprint requests should be addressed. Fax: +46317733910. E-mail: mikael.kubista@mol biotech.chalmers.se.
}

Traditional probes are single-stranded oligonucleotides labeled with a radioisotope or a fluorophore. The signals generated by these probes are independent of their hybridization state and separation of free and hybridized probe is required in the assay. The separation is time-consuming and complicated to automatize, and the probes are not suitable, for example, to monitor PCR product formation in real time. The separation step can be eliminated by a probe whose signal changes upon hybridization $(1,2)$ or which is degraded during the PCR amplification reaction $(3,4)$. One such probe is the molecular beacon $(5,6)$, which is an oligonudleotide having a fluorophore and a quencher attached to the $5^{\prime}$ and $3^{\prime}$ ends, respectively, designed to form a stem-andloop structure. U pon hybridization the oligonucleotide is straightened, which separates the quencher from the fluorophore, resulting in an increase in fluorescence. A similar design is employed in the so-called scorpions primers used for PCR product detection (7).

We here describe new kind of probes for homogeneous assays. We call them light-up probes. They are composed of thiazole orange $(\mathrm{TO})^{2}$ conjugated to peptide nucleic acid (PNA), and combine the excellent hybridization properties of PNA (8) with the extraordinary fluorescence enhancement of asymmetric cyanine dyes upon binding to nucleic acids (9). PNA binds sequence specifically to target nucleic acid bringing the dye to it. Figure 1 shows the chemical structure of the light-up probes. TO is covalently linked to the N-terminus $(\mathrm{H})$ of the PNA oligomer by a linker $(\mathrm{X})$ attached either to the quinoline (TO-N) or to the benzothiazole (TO-N') nitrogen of TO. The light-up probes can be synthesized either in aqueous solution by attaching a succinimidyl ester derivative of TO to PNA modified

\footnotetext{
${ }^{2}$ Abbreviations used: TO, thiazole orange; PNA, peptide nucleic acid; LUP, light-up probe; meq, mole equivalent; ACN, acetonitrile.
} 
with an amino linker or by coupling a carboxylic acid derivative of the dye directly to the terminal PNA residue during solid-phase synthesis (10).

The linker in the light-up probe is flexible, allowing the dye to interact with the target nucleic acid upon hybridization (Fig. 1). The dye can, however, also fold back interacting with the bases in the free probe, which might give rise to residual free probe fluorescence. In fact, one reason the light-up probes are based on PNA instead of normal oligodeoxyribonucleotides is that electrostatic attraction of the cationic TO dye is eliminated, minimizing this "back-binding."

Owing to the particular hybridization properties of PNA, the interaction of light-up probes with target nucleic acid depends on the probe sequence (Fig. 1). Mixed sequence probes are expected to form PNADNA duplexes while homopyrimidine probes should form PNA ${ }_{2}$-DNA triplexes $(11,12)$. Further, PNADNA duplexes can form both in parallel and in antiparallel orientation, and $\mathrm{PNA}_{2}$-DNA triplexes can form with the two PNA strands either parallel or antiparallel to the DNA. The PNA-DNA complexes vary considerably in thermal stability but are all much more stable than DNA duplexes (8).

\section{MATERIALS AND METHODS}

\section{Chemicals}

Oligonucleotides were purchased from Medprobe Inc. The molar absorptivities of oligonucleotides and of PNA were estimated as $\epsilon_{260} / 10^{3}=11.7 n_{G}+7.3 n_{c}+$ $15.4 n_{A}+8.8 n_{T} M^{-1} \mathrm{~cm}^{-1}$, where $n_{x}$ is the number of bases of type $X$ in the oligonucleotide (13). Concentrations of oligonucleotides and PNA are expressed in strands per volume.

\section{Probe Synthesis}

The dyes TO-N-5-COOH (N-carboxypentyl-4-[(3'methyl-1',3'-benzothiazol-2'-yl) methylenyl ]quinol inium iodide), TO-N-5-S (succinimidyl ester of $\mathrm{N}$-carboxypentyl-4-[(3'-methyl-1', 3' -benzothiazol-2' -yl)methylenyl]quinolinium iodide), and TO-N'-10-COOH (N-methyl-4-[(3'-carboxydecyl-1', 3' -benzothiazol-2' yl)methylenyl ]quinol inium iodide) were synthesized by a somewhat modified procedure of Zhou et al. (14). The benzothiazolium and quinolinium salts of the dyes were prepared via quaternization by heating equimolar amount of the heterocyclic compound (2-methylbenzothizole or quinoline) with either methyl p-toluene sulfonate or $\gamma$-bromocarboxylic acid (5-bromohexanoic acid or 10 -bromoundecanoic acid) at $110^{\circ} \mathrm{C}$ for $4 \mathrm{~h}$. The methyl salts were obtained in almost $100 \%$ yields and the $\gamma$-carboxylic acid salts were obtained in 20-60\% yield. The dyes were synthesized in $20-40 \%$ yield by condensation of the corresponding benzothiazolium and quinolinium salts by stirring equimolar amounts of the two salts and five mole equivalents of triethylamine $\left(\mathrm{Et}_{3} \mathrm{~N}\right)$ in dichloromethane at room temperature overnight. The reactions were quenched by addition of $30 \% \mathrm{KI}_{\text {aq }}$ solution and the products were purified by recrystallization from $\mathrm{MeOH} / \mathrm{H}_{2} \mathrm{O}$.

The PNAs were synthesized by solid-phase synthesis as described elsewhere (10) and the carboxylic acid derivatives of the dyes were coupled to the terminal residue as follows. Ten to $20 \mathrm{mg}$ t-Boc protected resinbound PNA $(\approx 0.15 \mathrm{mmol} / \mathrm{g})$ was swelled overnight in dichloromethane. The t-Boc protection groups were cleaved with TFA:m-cresol (95:5) and the resin was washed with dichloromethane:DMF (50:50) and pyridine. Five mole equivalents (meq) of dye in $300 \mu \mathrm{l}$ DMF mixed with 4.5 meq HBTU (2-(1H-benzotriazole-1-yl)1,1,3,3-tetrametyluronium hexafluorophosphate) and $4 \mu \mathrm{l}$ di-isopropylethylamine was added. Nitrogen gas was passed through the solution and the coupling re action proceeded for $2 \mathrm{~h}$ at room temperature. The probes were cleaved from the resin by two repeated 1-h incubations with m-creosol:thioanisole:TFMSA:TFA (1:1:2:6) and precipitated in ice-cold dry ether. The white solid was finally resuspended in $100 \mu$ l water, which resulted in a clear red solution. One of the light-up probes (LUP5) was synthesized in aqueous solution by attaching TO-N-5-S to PNA modified with an aminohexanoic (-aha-) linker at the $\mathrm{N}$-terminus $(\mathrm{H})$. Forty nanomoles PNA ( $\mathrm{H}$-aha-TTCTTCTTTT- $\mathrm{NH}_{2}$ ) was dissolved in a mixture of $50 \mu \mathrm{l} 200 \mathrm{mM}$ borate buffer (pH 9.0) and $20 \mu$ l dioxane. Then $2 \times 200 \mathrm{nmol}$ TO-N-5-S in DMSO was added and the reaction mixture was stirred. After $2 \mathrm{~h}$ at $37^{\circ} \mathrm{C}$ the reaction was quenched by addition of $10 \mu \mathrm{l}$ of $5 \mathrm{M}$ ammonium acetate and the mixture was heated to $90^{\circ} \mathrm{C}$ for $10 \mathrm{~min}$.

The probes were purified on an RP $\mathrm{C}_{18}$ HPLC column (Waters Symmetry $3.9 \mathrm{~mm} \times 15 \mathrm{~cm}$ ) using an acetonitrile $(\mathrm{ACN}) / \mathrm{H}_{2} \mathrm{O}$ gradient containing $0.1 \%$ trifluoroacetic acid (ACN : $5 \% \rightarrow 40 \%, 20 \mathrm{~min} ; 40 \% \rightarrow 100 \%, 5 \mathrm{~min}$; $100 \%, 5 \mathrm{~min})$. Yields of dye attachment exceeded in all cases $50 \%$. The pure probe fractions were freeze-dried, redissolved in water at about $1 \mathrm{mM}$ concentrations, and stored in dark at $-20^{\circ} \mathrm{C}$.

\section{Polymerase Chain Reaction}

A 355-bp DNA fragment containing the target sequence for light-up probe LUP5, doned in the Pstl site in the polylinker of Bluescript $\mathrm{KS}^{+}$, was produced by PCR using $1 \mathrm{ng}$ of template ( $10^{9}$ molecules) and the primers 5'-AAAGGGGGATGTGCTGCAAGGCG-3' and 5'-GCTTCCGGCTCGTATGTTGTGTG-3'. The PCR reaction buffer contained $10 \mathrm{mM}$ Tris (pH 8.3), $50 \mathrm{mM} \mathrm{KCl}, 2.5$ $\mathrm{mM} \mathrm{MgCl}{ }_{2}, 0.3 \mu \mathrm{M}$ of each primer, 50 units $/ \mathrm{ml}$ of Taq DNA polymerase (Sigma), and $200 \mu \mathrm{M}$ of each dNTP. The cycle $94^{\circ} \mathrm{C}(45 \mathrm{~s}), 55^{\circ} \mathrm{C}(45 \mathrm{~s})$ and $72^{\circ} \mathrm{C}$ (45 s) was 
a
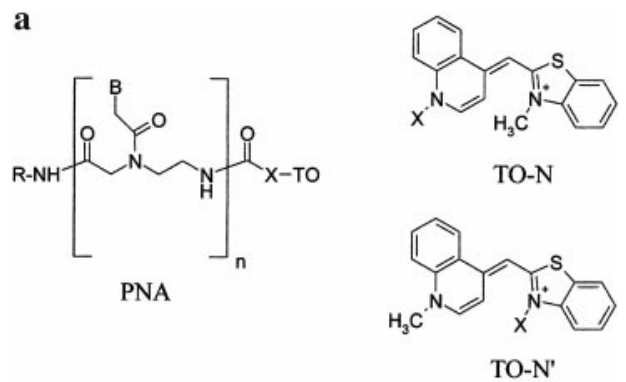

b

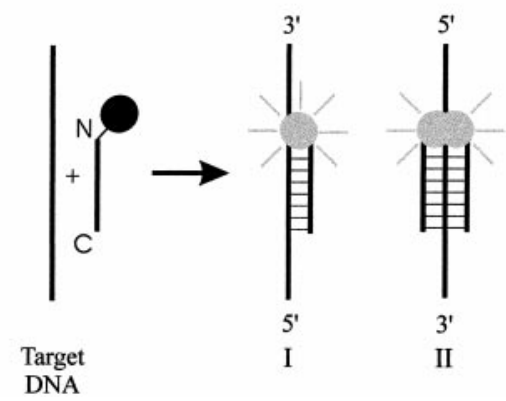

FIG. 1. (a) Chemical structure of light-up probes. B denotes nucleobases and $\mathrm{R}$ is $\mathrm{H}$, Iysinyl amide, or lys-lysinyl amide. $\mathrm{X}$ denotes the linker which is either $\left(\mathrm{CH}_{2}\right)_{5}-\mathrm{NH}-\mathrm{CO}-\left(\mathrm{CH}_{2}\right)_{5}$ or $\left(\mathrm{CH}_{2}\right)_{y}$ where y is 5 or 10. The linker is attached either to the quinoline (TO-N) or benzothiazole (TO-N') nitrogen of thiazole orange. (b) Schematic showing how mixed sequence (I) and homopyrimidine (II) light-up probes may interact with single-stranded target nucleic acid.

repeated 30 times. Ninety-three microliters of the amplified samples was mixed with $2 \mu \mathrm{l}$ probe solution (final concentrations: $150 \mathrm{nM}$ probe and $5 \mathrm{mM} \mathrm{MgCl}_{2}$ ).

\section{Absorption and Fluorescence Measurements}

The probes were studied in $10 \mathrm{mM}$ phosphate buffer, $100 \mathrm{mM} \mathrm{NaCl}$ at pH 7.0. The samples were prepared in a standard 1-cm square quartz cell and degassed with helium. For the PCR samples a reduced volume (70 $\mu \mathrm{l})$ cell was used. Absorption spectra were recorded on a Varian Cary 4 spectrometer using $1 \mathrm{~nm}$ bandwidth, and fluorescence emission spectra were recorded on a SPEX Fluorolog $\tau 2$ spectrofluorometer using $470 \mathrm{~nm}$ excitation and a bandwidth of 3.6-4.8 nm. For the PCR samples 480-nm excitation and a 9-nm bandwidth were used. Absorption at excitation wavelength never exceeded 0.06 making the inner filter effect negligible (15). Contribution from buffer, which for the PCR samples also included Taq polymerase, primers, and dNTP's, was subtracted.

Molar absorptivities of the probes at $260 \mathrm{~nm}$ were estimated as the sum of the contributions from TO (7100 $\mathrm{M}^{-1} \mathrm{~cm}^{-1}(16)$ ) and from PNA, assuming the same extinction coefficients of the PNA bases as in deoxyribooligonucleotides. Fluorescence quantum yields were determined relative to fluorescein in $0.1 \mathrm{M}$ $\mathrm{NaOH}$ assuming a quantum yield of 0.93 for the fluorescein dianion (17). The probe-DNA thermal melting temperatures $\left(T_{m}\right)$ were determined by absorption at $260 \mathrm{~nm}$. The temperature was increased at a rate of $0.5^{\circ} \mathrm{C} / \mathrm{min}$ and the measured signal was digitized to 1 data point per ${ }^{\circ} \mathrm{C} . \mathrm{T}_{\mathrm{m}}$ was determined as the maximum of the first derivative of the melting curve.

\section{RESULTS}

\section{Spectroscopic Properties of Light-Up Probes}

Figure 1 shows the basic structure of the light-up probes (LUP) and their assumed mode of interaction with target nucleic acids. The probe stem is a PNA, which is a chain of standard nucleobases joined by $\mathrm{N}$-(2-aminoethyl)glycine units. The asymmetric cyanine dye TO is tethered to the PNA. A few different chemical compositions of the linker are tested and it is attached either to the quinoline (TO-N) or to the benzothiazole (TO-N') nitrogen of the dye. The sequences, linkers, and dyes used in the probes are shown in Table 1. The PNA is 5 to 15 bases in length, and in some probes one or two lysine residues are attached to the PNA C-terminus $\left(\mathrm{NH}_{2}\right)$ to improve PNA solubility (18). LUP1, LUP2, LUP6, LUP7, and LUP8 are mixed se-

TABLE 1

Composition of the Light-Up Probes

\begin{tabular}{|c|c|c|}
\hline Probe & $\begin{array}{c}\text { PNA sequence } \\
\text { (C) }\end{array}$ & $\begin{array}{l}\text { Linker/dye } \\
\text { (N) }\end{array}$ \\
\hline LUP1 & Lys ${ }^{+}-T A G C T--$ & $--\mathrm{CO}-\left(\mathrm{CH}_{2}\right)_{5}-\mathrm{TO}-\mathrm{N}$ \\
\hline LUP2 & Lys $^{+}-$TAGCTGCT-- & $--\mathrm{CO}-\left(\mathrm{CH}_{2}\right)_{5}-\mathrm{TO}-\mathrm{N}$ \\
\hline LUP3 & Lys $^{+}$-CTCCTTCTCC-- & $--\mathrm{CO}-\left(\mathrm{CH}_{2}\right)_{10}-\mathrm{TO}-\mathrm{N}^{\prime}$ \\
\hline LUP4 & TTTTCTTCTT-- & $-\mathrm{CO}-\left(\mathrm{CH}_{2}\right)_{5}-\mathrm{TO}-\mathrm{N}$ \\
\hline LUP5 $^{\mathrm{a}}$ & TTTTСТTСТT-- & $-\mathrm{CO}-\left(\mathrm{CH}_{2}\right)_{5}-\mathrm{NH}-\mathrm{CO}-\left(\mathrm{CH}_{2}\right)_{5}-\mathrm{TO}-\mathrm{N}$ \\
\hline LUP6 & Lys ${ }^{+}-$TAGCTGCTCTT-- & $-\mathrm{CO}-\left(\mathrm{CH}_{2}\right)_{5}-\mathrm{TO}-\mathrm{N}$ \\
\hline LUP7 & TTTTCTTCTTATGCT-- & $-\mathrm{CO}-\left(\mathrm{CH}_{2}\right)_{5}-\mathrm{TO}-\mathrm{N}$ \\
\hline LUP8 & Lys $^{+}$-Lys ${ }^{+}$-ATCAACACTGCATGT-- & $--\mathrm{CO}-\left(\mathrm{CH}_{2}\right)_{10}-\mathrm{TO}-\mathrm{N}^{\prime}$ \\
\hline
\end{tabular}

a Synthesized in aqueous solution. 


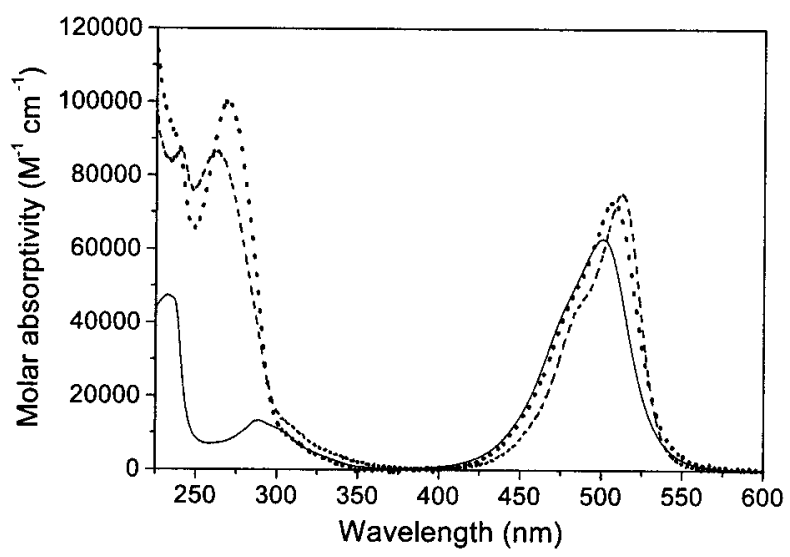

FIG. 2. Absorption spectra of free TO (-) and of free LUP2 (---) and LUP3 (..). $\mathrm{T}=25^{\circ} \mathrm{C}$.

quence probes forming duplexes with single-stranded nucleic acid target, while LUP3, LUP4, and LUP5 are homopyrimidine probes expected to form (LUP) $)_{2}$-DNA triplexes $(11,12)$.

Fluorescence and absorption of the free probes was measured at 0.4-1.2 $\mu \mathrm{M}$ probe concentration. Some probes had a tendency to adsorb to cell and tube walls and losses were minimized by using the same cell for absorption and fluorescence measurements. Figure 2 shows absorption spectra of LUP2, LUP3, and of free $\mathrm{TO}$ at $25^{\circ} \mathrm{C}$. F ree $\mathrm{TO}$ absorbs mainly in the VIS region having absorption maximum at $501 \mathrm{~nm}$ and a molar absorptivity of $63,000 \mathrm{M}^{-1} \mathrm{~cm}^{-1}(16)$. Both TO $\left(\lambda_{\max }^{\text {LUP2 }}=\right.$ $\left.512, \lambda_{\max }^{\text {LUP3 }}=506 \mathrm{~nm}\right)$ and PNA $\left(\lambda_{\max }^{\text {LUP }}=260, \lambda_{\max }^{\text {LUP }}=270\right.$ $\mathrm{nm})$, whose absorption depends on the sequence, contribute to the probe absorption. The TO absorption in the VIS region is red-shifted and it has a somewhat higher molar absorptivity than free TO (Fig. 2).

LUP2, which has the most red-shifted TO absorption, also has a pronounced shoulder around $485 \mathrm{~nm}$.
At $25^{\circ} \mathrm{C}$ both these probes are more fluorescent than free TO, having fluorescence quantum yields $\left(\Phi_{\mathrm{F}}\right)$ of 0.0089 (LUP2) and 0.0015 (LUP3), while free TO has 0.0002 (16). The spectroscopic properties of the light-up probes are summarized in Table 2. The free probe fluorescence at $25^{\circ} \mathrm{C}$ varies among the probes. In general, homopyrimidine probes (LUP3, LUP4, and LUP5) have low free probe fluorescence $\left(\Phi_{\mathrm{F}}^{25^{\circ} \mathrm{C}}=\right.$ $0.0015-0.0064)$, while large variation is observed for the mixed sequence probes. LUP1 and LUP2 exhibit as low free probe fluorescence $\left(\Phi_{\mathrm{F}}^{25^{\circ} \mathrm{C}}=0.0024-0.0089\right)$ as the homopyrimidine probes, while LUP7 and LUP8 exhibit significantly higher fluorescence $\left(\Phi_{\mathrm{F}}^{25^{\circ} \mathrm{C}}=\right.$ $0.060-0.083$ ). Further, the wavelength at absorption maximum varies among the probes. The homopyrimidine probes absorb at shorter wavelengths $\left(\lambda_{\max }=\right.$ 506-507) than the mixed-sequence probes ( $\lambda_{\max }=508$ 514). Although probes that absorb at longer wavelengths tend to have high free probe fluorescence (Table 2), there are exceptions. LUP2 and LUP8, for example, are both shifted to the same extent $\left(\lambda_{\max }^{\mathrm{LUP2}}=\right.$ $512 \mathrm{~nm}, \lambda_{\max }^{\text {LUP8 }}=514 \mathrm{~nm}$ ) but LUP8 is 10 times more fluorescent than LUP2.

As a rule, free probe fluorescence decreases when temperature is increased (Table 2). The $\Phi_{\mathrm{F}}^{\mathrm{free}, 25^{\circ} \mathrm{C}} / \Phi_{\mathrm{F}}^{\mathrm{free}, 50^{\circ} \mathrm{C}}$ ratio, however, varies among the probes. F or LUP8 the fluorescence quantum yield decreases about twofold, while for LUP5 and LUP7 the decrease is sixfold (Table 2).

\section{Specific Detection of Nucleic Acids in Homogeneous Solution}

An equimolar amount of either complementary or noncomplementary ol igonucl eotide was added to LUP2 $(0.2 \mu \mathrm{M})$ and LUP3 $(0.5 \mu \mathrm{M})$ at 30 and $50^{\circ} \mathrm{C}$, respectively. The complementary oligonucleotide added to LUP2 had the target sequence in position 1 through 8 of 18 bases and the one added to LUP3 had it in

TABLE 2

Spectroscopic Properties of Free and Hybridized Light-Up Probes

\begin{tabular}{|c|c|c|c|c|c|c|c|c|c|}
\hline \multirow[b]{2}{*}{ Probe } & \multirow[b]{2}{*}{$\lambda_{\max }^{\mathrm{free}}$} & \multirow[b]{2}{*}{$\lambda_{\max }^{\text {hyb }}$} & \multicolumn{3}{|c|}{$25^{\circ} \mathrm{C}$} & \multicolumn{3}{|c|}{$50^{\circ} \mathrm{C}$} & \multirow[b]{2}{*}{$\Phi_{\mathrm{F}}^{\text {free, } 25^{\circ} \mathrm{C}} / \Phi_{\mathrm{F}}^{\text {free, } 50^{\circ} \mathrm{C}}$} \\
\hline & & & $\Phi_{\mathrm{F}}^{\mathrm{free}}$ & $\Phi_{\mathrm{F}}^{\text {hyb }}$ & $\Phi_{\mathrm{F}}^{\text {hyb }} / \Phi_{\mathrm{F}}^{\text {free }}$ & $\Phi_{\mathrm{F}}^{\text {free }}$ & $\Phi_{\mathrm{F}}^{\text {hyb }}$ & $\Phi_{\mathrm{F}}^{\text {hyb }} / \Phi_{\mathrm{F}}^{\text {free }}$ & \\
\hline TO & 501 & - & $2 \times 10^{-4}$ & - & - & - & - & - & - \\
\hline LUPI & 508 & $-^{a}$ & 0.0024 & $-^{a}$ & - & $6.3 \times 10^{-4}$ & $-^{a}$ & - & 3.8 \\
\hline LUP2 & 512 & 514 & 0.0089 & 0.14 & 16 & 0.0035 & 0.073 & 21 & 2.5 \\
\hline LUP3 & 506 & 512 & 0.0015 & 0.068 & 45 & $5.8 \times 10^{-4}$ & 0.025 & 43 & 2.6 \\
\hline LUP4 & 507 & 512 & 0.0064 & 0.042 & 7 & 0.0016 & 0.017 & 11 & 4.0 \\
\hline LUP5 $^{\mathrm{b}}$ & 507 & 512 & 0.0059 & 0.057 & 10 & 0.0010 & 0.018 & 18 & 5.9 \\
\hline LUP6 & 510 & 514 & 0.017 & 0.083 & 5 & 0.0072 & 0.034 & 5 & 2.4 \\
\hline LUP7 & 511 & 513 & 0.060 & 0.14 & 2 & 0.010 & 0.047 & 5 & 6.0 \\
\hline LUP8 & 514 & 514 & 0.083 & 0.063 & 0.8 & 0.037 & 0.025 & 0.7 & 2.2 \\
\hline
\end{tabular}

${ }^{a}$ Not studied.

${ }^{\mathrm{b}}$ Hybridized to target in parallel orientation. The data are from a separate temperature study of LUP5. 

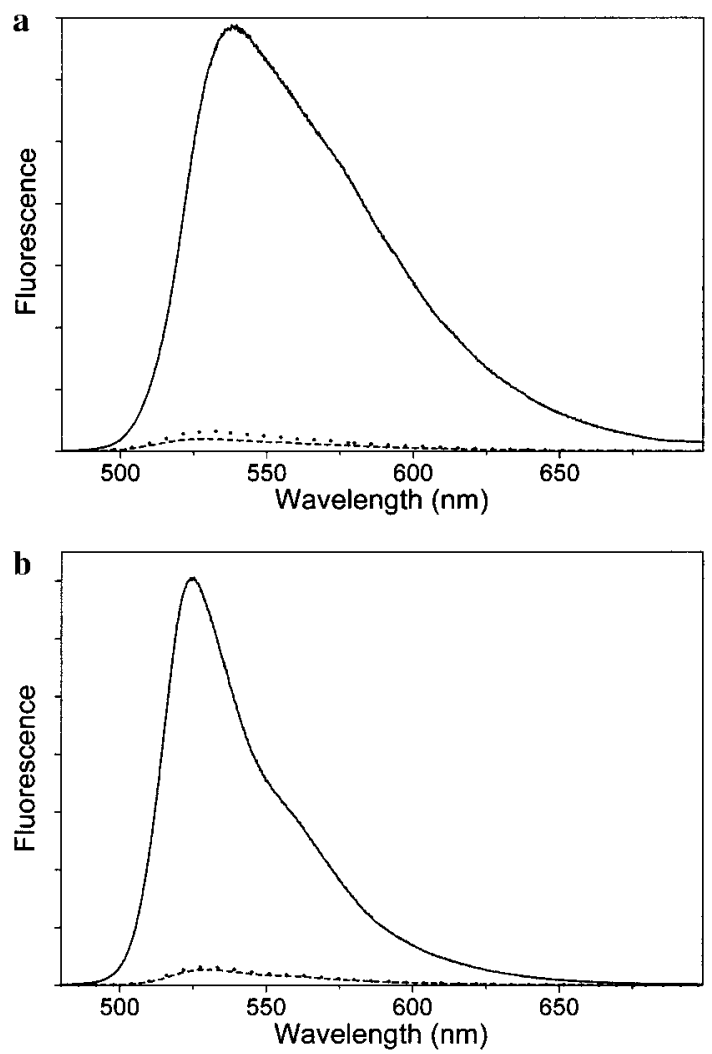

FIG. 3. (a) Fluorescence emission spectra of free LUP3 (---) and LUP3 in presence of noncomplementary (...) and complementary (-) single-stranded oligonucleotides. The DNA sequences were 5' AGTGTTCCAATCAATAGCCTCTTCCTCATCTGTC-3' and 5'-GACAGATGAGGAAGAGGCTATTGATTGGAACACT- $3^{\prime} . \mathrm{T}=50^{\circ} \mathrm{C}$. (b) Fluorescence emission spectra of free LUP2 (---) and LUP2 in presence of complementary single-stranded oligonucleotide $(-)$ and an oligonucleotide with two mismatches (. . .). The DNA sequences were 5'-ATCGACGAGAGAATATCA-3' and 5'-CACGTATCCAAGAGAGAATAC-3'. T $=30^{\circ} \mathrm{C}$.

position 8 through 17 of 34 bases. The noncomplementary oligonucleotide added to LUP3 was truly noncomplementary, while the one added to LUP2 was designed having a stretch with 6 of 8 bases complementary to the probe to test stringency. Figure 3 shows fluorescence emission spectra of the probes recorded before and after addition of oligonucleotides. Addition of noncomplementary oligonucleotides hardly affected the probe fluorescence while addition of complementary oligonucleotides resulted in a 35- and 25fold increase in fluorescence intensity for LUP3 and LUP2, respectively. This demonstrates that both mixed sequence and homopyrimidine light-up probes bind specifically to their target sequences and report their presence with high sensitivity.

Light sources of standard UV illumination tables deliver light that excites the light-up probes. Figure 4 shows two samples containing LUP2 in polypropylene PCR tubes placed over a UV illumination table. The sample volume is $20 \mu \mathrm{l}$ and the probe concentration is $11 \mu \mathrm{M}$. The right tube contains equimolar amounts of a complementary oligonucleotide while the left tube contains fivefold excess of a noncomplementary oligonucleotide. The fluorescence emitted from the right tube is readily observed by the naked eye while no fluorescence is seen from the left tube.

\section{Spectroscopic Properties of Hybridized Light-Up Probes}

The light-up probes were hybridized to complementary oligonucleotides that all had the same overhang to which TO could bind ( $5^{\prime}$-[target sequence]-GACAGCTGGCGA-3'). The target oligonucleotides and probes were designed such that LUP2, LUP6, LUP7, and LUP8 formed antiparallel duplexes, LUP3 and LUP4 formed triplexes with the PNA strands antiparallel to the target oligonucleotide, and LUP5 formed a parallel triplex (the oligonucleotide having opposite orientation). Probe concentrations were 0.4-1.2 $\mu \mathrm{M}$ and oligonucleotide was added in slight excess at $90^{\circ} \mathrm{C}$. Hybridization took place during $20 \mathrm{~min}$ while the temperature was lowered to $25^{\circ} \mathrm{C}$, whereafter absorption and fluorescence emission spectra were recorded and fluorescence quantum yields were calculated. The hybridization procedure was then repeated but this time measuring spectra at $50^{\circ} \mathrm{C}$ instead of at $25^{\circ} \mathrm{C}$. Results from the hybridization studies with all probes but LUP1, which is too short to bind sequence specifically, are summarized in Table 2. Most probes exhibited a large increase in fluorescence quantum yield upon hybridization. For all probes but LUP7 and LUP8 the increase at $25^{\circ} \mathrm{C}$ was more than 5-fold; for LUP3 it was even 45-fold ( $\Phi_{\mathrm{F}}^{\text {free }}=0.0015, \Phi_{\mathrm{F}}^{\text {hyb }}=0.068$ ). The fluorescence quantum yield of the hybridized probes $\left(\Phi_{\mathrm{F}}^{\text {hyb }}=0.042-0.14\right)$ varied much less than that of the free probes $\left(\Phi_{\mathrm{F}}^{\text {free }}=0.0015-0.083\right)$. The fluorescence increase upon hybridization was accompanied by a redshift of the TO absorption (Table 2). LUP8 differed from the other probes by not exhibiting any red-shift or fluorescence increase upon addition of target oligonucleotide. With the homopyrimidine probes (LUP3, LUP4, and LUP5) the wavelength at TO absorption maximum shifted about $5 \mathrm{~nm}$, from 507 to $512 \mathrm{~nm}$, upon hybridization, while the absorption maximum of mixed sequences probes (LUP2, LUP6, LUP7, and LUP8) shifted to 513-514 nm. The increase in fluorescence and the shift in TO absorption evidence changes in the TO environment upon hybridization.

Probe fluorescence also depends on temperature in hybridized state. Increasing the temperature decreases the fluorescence (Table 2). For most probes the decrease in fluorescence when raising the temperature from 25 to $50^{\circ} \mathrm{C}$ was less in the hybridized than in the 


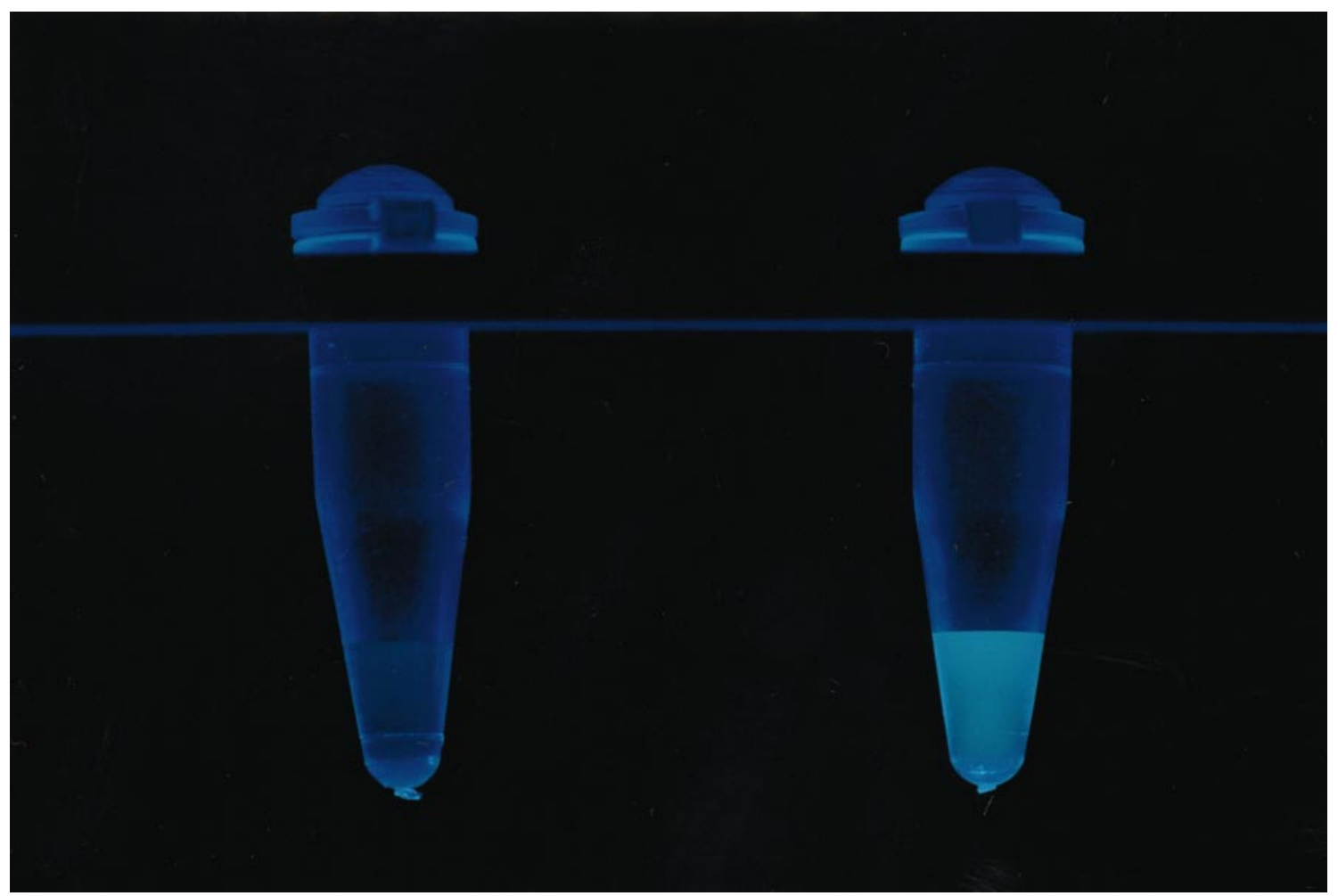

FIG. 4. 20- $\mu$ l samples in polypropylene PCR tubes placed over a UV illumination table. Both samples contain $11 \mu \mathrm{M}$ LUP 2 in $100 \mathrm{mM} \mathrm{NaCl}$, $10 \mathrm{mM}$ phosphate buffer, $\mathrm{pH}$ 7.0. The left tube contains also $55 \mu \mathrm{M}$ of a noncomplementary single-stranded oligonucleotide (5'-TCCTTCATTCGCTTC-3') and the right tube contains $11 \mu \mathrm{M}$ of complementary single-stranded DNA (5'-ATCGACGAGACAGCTGGCGA-3'). The tubes were photographed using ASA 400 film.

free state, resulting in a larger fluorescence enhancement upon hybridization at $50^{\circ} \mathrm{C}$ (Table 2).

\section{Mismatch Sensitivity}

The probe LUP5, which exhibited large fluorescence enhancement upon hybridization with target nucleic acid, was chosen for further characterization. Emission and absorption spectra of free probe $(0.9 \mu \mathrm{M})$ were recorded every $5^{\circ} \mathrm{C}$ between 20 and $90^{\circ} \mathrm{C}$ and fluorescence quantum yields were calculated (Fig. 5a). At $20^{\circ} \mathrm{C} \Phi_{\mathrm{F}}$ was 0.0083 . Increasing the temperature to $55^{\circ} \mathrm{C}$ dropped the fluorescence 10 -fold, and at $90^{\circ} \mathrm{C}$ it reached the level of free TO $\left(\Phi_{\mathrm{F}}=0.0002\right)$. Hence, the total decrease in fluorescence was about 40-fold. Equimolar amounts of oligonucleotide 5'-AGCGGTCGACAGAANAAGAAAA-3', with $N$ being either $\mathrm{G}$ or $\mathrm{T}$, was added to LUP5. The "G" oligonucleotide is fully complementary in parallel orientation to the probe and is expected to form a (LUP5) $)_{2}$-DNA triplex, while the " $T$ " oligonucleotide has a single mismatch in position 8 in the 10 base target sequence. The complementary oligonucleotide was added to a cell containing $0.9 \mu \mathrm{M}$ LUP5 at $90^{\circ} \mathrm{C}$, and the temperature was lowered to $20^{\circ} \mathrm{C}$ during $20 \mathrm{~min}$ for hybridization to take place. The temperature was raised again and absorption spectra were recorded every $5^{\circ} \mathrm{C}$ between 20 and $90^{\circ} \mathrm{C}$. The procedure was then repeated but this time recording fluorescence emission spectra. Finally, the same measurements were performed on LUP5 in the presence of the mismatched target. From the combined spectroscopic data fluorescence quantum yields were calculated. With both targets the fluorescence decreased with temperature. With the mismatched target the fluorescence reached the level of free probe around $65^{\circ} \mathrm{C}$ and with the complementary target around $85^{\circ} \mathrm{C}$ (Fig. 5a). This reflects different melting temperatures $\left(T_{m}\right)$ in the two probe-target oligonucleotide complexes, which were in a separate experiment determined to 48 and $78^{\circ} \mathrm{C}$. Hence, in the range 50 to $75^{\circ} \mathrm{C}$ the probe fluorescence is substantially higher in presence of the fully complementary ol igonucleotide than in the presence of an oligonucleotide having a single mismatch. Figure $5 b$ shows the ratios of the fluorescence quantum yields of LUP5 in the presence and in the absence of the target oligonucleotides. The largest increase in fluorescence quantum yield upon addition of the complementary target is about 18-fold and is ob- 

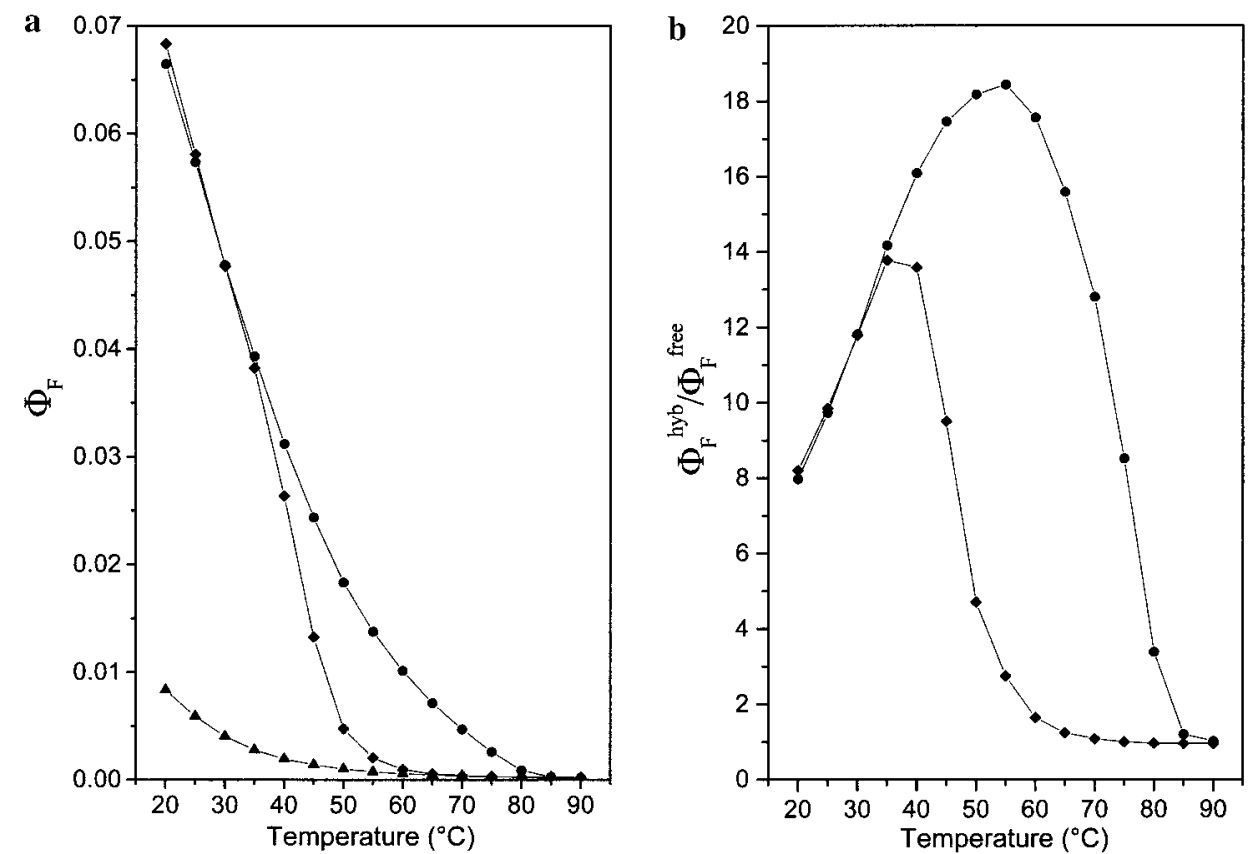

FIG. 5. (a) Fluorescence quantum yield of free LUP5 ( $\mathbf{\Delta})$ and of LUP5 in presence of complementary $(\mathbf{\bullet})$ and mismatched $(\bullet)$ oligonucl eotide as function of temperature. (b) Enhancement of fluorescence $\left(\Phi_{\mathrm{F}}^{\text {hyb }} / \Phi_{\mathrm{F}}^{\text {free }}\right)$ for LUP5 in the presence of complementary $(\mathbf{0})$ and mismatched $(\diamond)$ oligonucleotides as a function of temperature. The lines are shown to guide the eye.

served at $55^{\circ} \mathrm{C}$. At this temperature the mismatched target gives only a 3 -fold increase in fluorescence.

\section{Post-PCR Detection}

The light-up probes were tested on PCR products. Three samples were prepared: a reference sample containing only buffer (10 mM Tris- $\mathrm{HCl}, \mathrm{pH} 8.3,50 \mathrm{mM}$ $\mathrm{KCl}$ ), a "negative sample" containing 1 ng calf thymus DNA, and a "positive sample" also containing 1 ng $\left(10^{9}\right.$ molecules) plasmid having the LUP5 target sequence. Taq polymerase, dNTP's, $\mathrm{MgCl}_{2}$, and primers, encompassing the target sequence, were added and a 355-bp segment of the plasmid was amplified in 30 cycles. LUP5 was then added to a final concentration of 150 $\mathrm{nM}$. The samples were heated to $95^{\circ} \mathrm{C}$ for $1.5 \mathrm{~min}$ and cooled to $65^{\circ} \mathrm{C}$ before emission spectra were measured (Fig. 6). The reference and negative samples had essentially the same fluorescence, while the fluorescence of the positive sample was three times higher.

\section{DISCUSSION}

\section{Fluorescence of Free Light-Up Probes}

At $25^{\circ} \mathrm{C}$ absorption maxima of free light-up probes $\left(\lambda_{\max }^{25^{\circ} \mathrm{C}}=506-514 \mathrm{~nm}\right)$ are red-shifted relative to that of free TO $\left(\lambda_{\max }^{\mathrm{TO}}=501 \mathrm{~nm}\right)$. A similar red-shift is observed for monomeric TO bound to DNA $\left(\lambda_{\max }^{\mathrm{TO}-\mathrm{DNA}}=507-511\right)$ (16). Some of the free probe spectra also exhibit shoulders around $485 \mathrm{~nm}$ that are not observed for free TO
(Fig. 2), but appear when TO binds to DNA (16). Further, the free probes exhibit higher fluorescence than free TO (Table 2). The similar spectroscopic features of free probes at $25^{\circ} \mathrm{C}$ and of monomeric TO bound to single-stranded DNA suggest that TO in the free probe is not unrestrictedly free in solution, but folds back interacting to some extent with the PNA bases. Considering that cationic intercalators bind very weakly, if at all, to PNA (19) this may seem surprising. However, in the light-up probe TO is tethered to the PNA, which

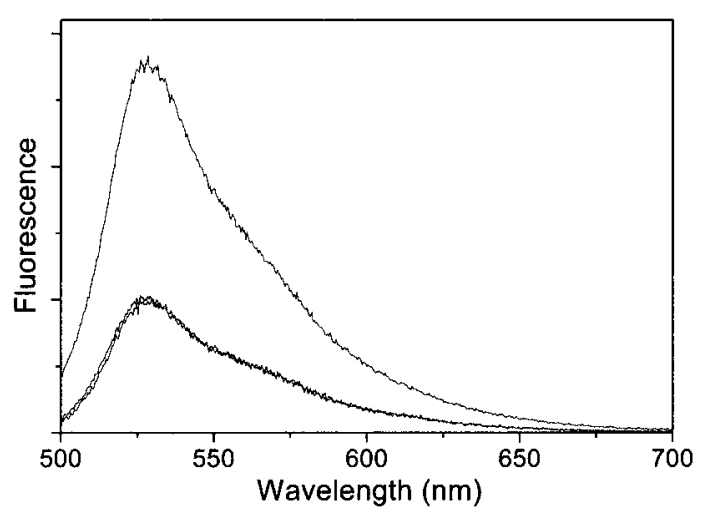

FIG. 6. Fluorescence emission spectra of PCR amplified samples containing 150 nM LUP5. The samples contained buffer (low intensity), calf thymus DNA (1 ng) (low intensity, line is overlaid), and amplified template in the presence of calf thymus DNA (1 ng) (high intensity), respectively. 
results in a very high "local" TO concentration in the vicinity of the PNA, shifting the equilibrium toward bound species. The decrease in free probe fluorescence when temperature is raised (Table 2 and Fig. $5 a$ ) is due to reduced residual back-binding of TO to the PNA. At $90^{\circ} \mathrm{C}$, back-binding is totally eliminated and the free probe fluorescence is as low as that of free TO (LUP5, Fig. 5a).

We expected that structurally similar probes, i.e., probes with the same linker and the same dye attachment (TO-N or TO-N'), would exhibit similar spectroscopic properties. However, this was not the case (Tables 1 and 2). LUP3 and LUP8, which have the same linker and point of dye attachment (TO-N'), exhibit extreme free probe fluorescence responses $\left(\Phi_{\mathrm{F}}^{25^{\circ} \mathrm{C}}=\right.$ 0.0015 for LUP3 and $\Phi_{\mathrm{F}}^{25^{\circ} \mathrm{C}}=0.083$ for LUP8) (Table 2 ). Both LUP4 and LUP7, which have short linker and the TO-N dye (Table 1), exhibit 10-fold difference in free probe fluorescence (Table 2). Clearly, the linker length and dye attachment does not determine the free probe fluorescence. Nor does the free probe fluorescence correlate with the length of the PNA or the presence of Iysine residues (Table 2). Hence, neither the length of PNA, the linker length, the mode of TO attachment nor the presence of lysines has a major effect on the free probe fluorescence. LUP4 and LUP5, which have different linkers but the same PNA sequence (Table 1), exhibit similar spectroscopic properties (Table 2), suggesting that the PNA sequence is an important determinant.

Homopyrimidine probes (LUP3-LUP5) exhibit very low free probe fluorescence $\left(\Phi_{\mathrm{F}}^{25^{\circ} \mathrm{C}}=0.0015-0.0064\right)$ (Table 2). They also have the smallest shift in absorption $\left(\lambda_{\max }^{25^{\circ} \mathrm{C}}=506-507 \mathrm{~nm}\right)$ relative to free TO $\left(\lambda_{\max }^{25^{\circ} \mathrm{C}}=\right.$ $501 \mathrm{~nm})$. This suggests that TO in these probes is mainly free in solution and does not interact significantly with the PNA, which is consistent with the generally very low affinity of TO for polypyrimidines (16). The variation in free probe fluorescence of probes containing all four nucleobases is considerably larger $\left(\Phi_{\mathrm{F}}^{25^{\circ} \mathrm{C}}=0.0024-0.083\right)$. The mixed sequence probes that have high free probe fluorescence (LUP7 and LUP8) also have strongly red-shifted absorption spectra. In these probes TO folds back interacting with the PNA bases to a higher extent, giving rise to fluorescence. Also LUP2 has a substantially red-shifted absorption spectrum $\left(\lambda_{\max }^{25^{\circ} \mathrm{C}}=512 \mathrm{~nm}\right)$, with a shape similar to that of bound TO (Fig. 2) (16). Still it has low fluorescence (Table 2). Having previously shown that TO binds to some single-stranded DNAs without acquiring fluorescence (16), we think TO in LUP2 is back-bound, interacting with the PNA bases, but in a way that does not give rise to fluorescence. Presently we do not know how different factors affect the extent of back-binding. The PNA sequence is clearly impor- tant, but the dependence is complex and extensive studies are required to reveal all of its aspects.

Fluorescence Enhancement of Light-Up Probes upon Hybridization

When light-up probes bind to target oligonucleotides, TO is brought to the DNA, interacting with the formed complex. For all probes but LUP8 this results in an increase in dye fluorescence, which is accompanied by a red-shift of the dye absorption band (Table 2). Similar spectral changes are seen when TO binds to DNA (16). In the hybridized state, the dye can either fold back, binding to the PNA-DNA duplex (or $\mathrm{PNA}_{2}$-DNA triplex), or it can bind to the protruding single-stranded DNA. We think the latter dominates since intercalating dyes in general have very low affinity for PNADNA duplexes (and PNA ${ }_{2}$-DNA triplexes) (19), while TO has substantial affinity for single-stranded DNA (16). Still the spectroscopic properties of the probes in the hybridized state varied slightly, although the protruding sequences were the same in all constructs (Table 2). The hybridized homopyrimidine probes (LUP3, LUP4, and LUP5) absorbed at shorter wavelength ( $\lambda_{\max }^{\text {hyb }}$ $=512)$ and had lower fluorescence $\left(\Phi_{\mathrm{F}}^{\text {hyb }}=\right.$ $0.042-0.068)$ than the mixed sequence probes $\left(\lambda_{\max }^{\text {hyb }}=\right.$ $\left.513-514, \Phi_{\mathrm{F}}^{\text {hyb }}=0.063-0.14\right)$. The reason could be that they form LUP $_{2}$-DNA triplexes with target DNA and that two TO dyes bind in close proximity to each another (Fig. 1). TO does bind to single-stranded DNA as both monomer and dimer, and it has different spectroscopic properties in the two binding modes: the bound dimer has a wider and more red-shifted emission spectrum than the bound monomer (16). This is in agreement with the emission spectra observed of the hybridized probes (Fig. 3). In LUP3, which is a homopyrimidine probe forming a $L U P_{2}-D N A$ triplex, the two TO chromophores exhibit broad emission, evidencing that they bind as a dimer. LUP2, which is a mixed sequence probe forming a PNA-DNA duplex, exhibits narrow TO emission. The fluorescence intensity of probes that should form the same complex with target DNA also varies. The quantum yield at $25^{\circ} \mathrm{C}$ of both LUP2 and LUP7 is 0.14 in hybridized state, while it is only 0.083 for LUP6. We do not know the reason for this difference, but TO in LUP6 seems to interact somewhat differently with target DNA than it does in LUP2 and LUP7.

In summary, the fluorescence quantum yield of the hybridized light-up probes characterized here varies about 4-fold $\left(\Phi_{\mathrm{F}}^{25^{\circ} \mathrm{C}}=0.042-0.14, \Phi_{\mathrm{F}}^{50^{\circ} \mathrm{C}}=0.017-0.073\right)$, while the free probe fluorescence varies more than 50 -fold $\left(\Phi_{\mathrm{F}}^{25^{\circ} \mathrm{C}}=0.0015-0.083, \Phi_{\mathrm{F}}^{50^{\circ} \mathrm{C}}=0.00058-0.037\right)$. Hence, we conclude that the fluorescence enhancement upon hybridization of the light-up probes is mainly determined by the free probe fluorescence (Table 2). 


\section{Light-Up Probes Are Sequence Specific}

Figure 3 shows that the light-up probes bind sequence specifically to target DNA. Addition of noncomplementary oligonucleotides or even an oligonucleotide with two mismatches did not affect the probe fluorescence at all. In a limited temperature range, light-up probes can be used to detect single base mismatches (Fig. 5), as indeed was expected owing to the very high sequence selectivity of PNA-DNA complexes $(8,11,20)$.

The fluorescence of hybridized LUP5 decreases about twofold (Fig. 5a) when the temperature is increased from 20 to $40^{\circ} \mathrm{C}\left(\Phi_{\mathrm{F}}^{20^{\circ} \mathrm{C}}=0.066, \Phi_{\mathrm{F}}^{40^{\circ} \mathrm{C}}=0.031\right)$, even though the probe is hybridized at both temperatures $\left(T_{m}=78^{\circ} \mathrm{C}\right)$. A similar decrease in fluorescence quantum yield is observed for TO bound to DNA under conditions where binding is quantitative (16). This effect of temperature is due to increased thermal motion of the DNA bases, which allows TO to move in its binding site, making nonradiative decay more efficient ther eby lowering the fluorescence (16). At higher temperature the fluorescence decreases also due to melting of the probe-target complex. Since the fluorescence of both the probe-target complex and the free probe decrease with temperature, the temperature dependence of the fluorescence enhancement upon hybridization is complex (Fig. 5b).

A single base change in a 10-base DNA target reduces the thermal stability of the complex with LUP5 by $30^{\circ} \mathrm{C}$. This results in a considerably lower fluorescence enhancement with a mismatched ol igonucleotide compared to a fully complementary one in the temperature range $45-75^{\circ} \mathrm{C}$ (Fig. 5b). The largest difference was obtained at $65^{\circ} \mathrm{C}$, where essentially no change in fluorescence $\left(\Phi_{\mathrm{F}}^{\mathrm{hyb}} / \Phi_{\mathrm{F}}^{\text {free }}=1.2\right)$ was observed with the mismatched target, while the fully complementary target enhanced the fluorescence 15 -fold.

\section{Light-Up Probes Are Suitable for Hybridization Assays in Homogeneous Solution}

The large enhancement in fluorescence upon hybridization makes the light-up probes particularly suitable for the detection of specific nucleic acids in diagnostic assays. With a fluorescence quantum yield of about 0.1 in hybridized state, picomolar concentrations of target nucleic acid can be detected using light-up probes in a regular spectrofluorometer (Fig. 3). Nanomolar range concentrations can be detected in a microtiterplate fluorescence reader, and micromolar concentrations are seen by the eye (Fig. 4).

In general, nucleic acids are amplified prior to detection. Since PNA-DNA hybrids are much more stable than corresponding DNA duplexes (8), light-up probe hybridization with target DNA efficiently out-competes reannealing of heat-denatured duplex DNA. This is demonstrated in Fig. 6 where a 10-nucleobase target is readily probed in competition with reannealing of a 355-bp PCR amplicon. In fact, heating may not even be necessary since PNA, under certain conditions, hybridizes to DNA by strand invasion (21-25).

\section{ACKN O WLEDGMENTS}

We thank Professor Peter Nielsen at the Department of Biochemistry, the Panum Institute, Dr. J an Nygren, Department of MolecuIar Biotechnology, Chalmers University of Technology, Dr. Robert Sjöback, Diffchamb AB and Dr. Ulrica Sehlstedt, LightUp Technologies AB for valuable discussions. This work was supported by the Swedish Research Council for Engineering Sciences.

\section{REFERENCES}

1. Yguerabide, J ., Talavera, E., Alvarez, J . M., and Afkir, M. (1996) Pyrene-labeled DNA probes for homogeneous detection of complementary DNA sequences: Poly(C) model system. Anal. Biochem. 241, 238-247.

2. Ishiguro, T., Saitoh, J ., Yawata, H., Otsuka, M., Inoue, T., and Sugiura, Y. (1996) Fluorescence detection of specific sequence of nucleic acids by oxazole yellow-linked oligonucleotides. Homogeneous quantitative monitoring of in vitro transcription. Nucleic Acids Res. 24, 4992- 4997.

3. Livak, K. J ., Flood, S. J ., Marmaro, J ., Giusti, W., and Deetz, K. (1995) Oligonucleotides with fluorescent dyes at opposite ends provide a quenched probe system useful for detecting PCR product and nucleic acid hybridization. PCR Methods Appl. 4, 357362.

4. Heid, C. A., Stevens, J ., Livak, K. J ., and Williams, P. M. (1996) Real time quantitative PCR. Genome Res. 6, 986-994.

5. Tyagi, S., and Kramer, F. R. (1996) Molecular beacons: Probes that fluoresce upon hybridization. Nat. Biotechnol. 14, 303-308.

6. Tyagi, S., Bratu, D. P., and Kramer, F. R. (1998) Multicolor molecular beacons for allele discrimination. Nat. Biotechnol. 16, 49-53.

7. Whitcombe, D., Theaker, J ., Guy, S. P., Brown, T., and Little, S. (1999) Detection of PCR products using self-probing amplicons and fluorescence. Nat. Biotechnol. 17, 804-807.

8. Egholm, M., Buchardt, O., Christiansen, L., Behrens, K., Freier, S. M., Driver, D. A., Berg, R. H., Kim, S. K., Nordén, B., and Nielsen, P. E. (1993) PNA hybridizes to complementary oligonucleotides obeying the Watson-Crick hydrogen-bonding rules. Nature 365, 566-568.

9. Haugland, R. P. (1996) Handbook of Fluorescent Probes and Research Chemicals (Spence, M. T. Z., Ed.), 6th ed. Molecular Probes Inc., Eugene, OR.

10. Christensen, L., Fitzpatrick, R., Gildea, B., Petersen, K. H., Hansen, H. F., Koch, T., Egholm, M., Buchardt, O., Nielsen, P. E., Coull, J ., et al. (1995) Solid-phase synthesis of peptide nucleic acids. J . Peptide Sci. 1, 175-183.

11. Egholm, M., Nielsen, P., Buchardt, O., and Berg, R. H. (1992) Recognition of guanine and adenine in DNA by cytosine and thymine containing peptide nucleic acids (PNA). J . Am. Chem. Soc. 114, 9677-9678.

12. Kim, S. K., Nielsen, P. E., Egholm, M., Buchardt, O., Berg, R. H., and Nordén, B. (1993) Right-handed triplex formed between peptide nucleic-acid PNA-T(8) and poly(dA) shown by linear and circular-dichroism spectroscopy. J . Am. Chem. Soc. 115, 64776481. 
13. Sambrook, J ., Fritsch, E. F., and Maniatis, T. (1989) Molecular Cloning, A Laboratory Manual, 2nd ed, p. 11.30. Cold Spring Harbor Laboratory Press, Cold Spring Harbor, NY.

14. Zhou, X.-f., Peng, Z-h., Geise, J ., Peng, B-X., Li, Z-X., Yan, M., Dommisse, R., Carieer, R., and Claeys, M. (1995) Blue sensitizing dyes: Synthesis, spectroscopy, and performance in photographic emulsions. J . I maging Sci. Technol. 39, 244-252.

15. Kubista, M., Sjöback, R., Eriksson, S., and Albinsson, B. (1994) Experimental correction for the inner-filter effect in fluorescence Spectra. Analyst 119, 417-419.

16. Nygren, J., Svanvik, N., and Kubista, M. (1998) The interactions between the fluorescent dye thiazole orange and DNA. Biopolymers 46, 39-51.

17. Sjöback, R., Nygren, J ., and Kubista, M. (1995) Absorption and fluorescence properties of fluorescien. Spectrochim. Acta 51, L 7L21.

18. Egholm, M., Buchardt, O., Nielsen, P. E., and Berg, R. H. (1992) Peptide nucleic acids (PNA). Oligonucleotide analogs with an achiral peptide backbone. J . Am. Chem. Soc. 114, 1895-1897.

19. Wittung, P., Kim, S. K., Buchardt, O., Nielsen, P., and Norden, B. (1994) Interactions of DNA binding ligands with PNA-DNA hybrids. Nucleic Acids Res. 22, 5371-5377.
20. Egholm, M., Christensen, L., Dueholm, K. L., Buchardt, O., Coull, J., and Nielsen, P. E. (1995) Efficient pH-independent sequence-specific DNA binding by pseudoisocytosine-containing bis-PNA. Nucleic Acids Res. 23, 217-222.

21. Nielsen, P. E., Egholm, M., Berg, R. H., and Buchardt, O. (1991) Sequence selective recognition by strand displacement with a thymine-substituted polyamid. Science 254, 14971500.

22. Nielsen, P. E., Egholm, M., and Buchardt, O. (1994) Evidence for (PNA)2/DNA triplex structure upon binding of PNA to dsDNA by strand displacement. J . Mol. Recognit. 7, 165-170.

23. Kuhn, H., Demidov, V. V., Nielsen, P. E., and Frank-Kamenetskii, M. D. (1999) An experimental study of mechanism and specificity of peptide nucleic acid (PNA) binding to duplex DNA. J. Mol. Biol. 286, 1337-1345.

24. Wittung, P., Nielsen, P., and Nordén, B. (1996) Direct observation of strand invasion by peptide nucleic acid (PNA) into doublestranded DNA. J . Am. Chem. Soc. 118, 7049-7054.

25. Wittung, P., Nielsen, P., and Norden, B. (1997) Extended DNArecognition repertoire of peptide nucleic acid (PNA): PNAdsDNA triplex formed with cytosine-rich homopyrimidine PNA. Biochemistry 36, 7973-7979. 